ISSN: 2162-3104 Print/ ISSN: 2166-3750 Online

Volume 7 Number 1 (2017), pp. 22-37

(C) Journal of International Students

http://jistudents.org/

\title{
International Graduate Students: Social Networks and Language Use
}

\author{
Daniel Moglen \\ University of California, Davis, USA
}

\begin{abstract}
The campus climate for international graduate students (IGSs) has been gaining attention in recent years as the number of IGSs in the United States continues to rise. IGSs bring diversity to the campus community and enrich the academic community, but also come to the table with distinct needs, concerns, and experiences. The current study is primarily concerned with how early social and academic experiences affect English learning and academic success. Social networks outside of the student's cultural background may be difficult to develop, and, therefore, it is not uncommon to see students gravitate towards others who share their cultural and language background. In order to obtain perspective on what early social and linguistic experiences are for newly matriculated IGSs, I conducted interviews with first-year IGSs, asking them about their language use in academic and social settings. Results from the interviews suggest that while English-oriented networks may provide more opportunities to speak in English, co-national networks are easier to join and provide much needed social and academic support.
\end{abstract}

Keywords: International Graduate Students, Second Language Learners, Social Networks, Second Language Acquisition

Brian, a first-year international graduate student from China, presented in the first-quarter ESL class in a clear, well-organized manner, and exuded confidence while he spoke. By all measures, his presentation combined with the other academic work that he produced indicated that he was on the track to academic success. I came to realize that, as the instructor of the class, it was not entirely clear to me how the presentation skills learned in my class would transfer to other academic classes, and in which ways this 
class would contribute to the overall language development of my students. Additionally, I later found out in an interview with Brian that he was socially isolated and not integrating easily into the local culture. Studies have suggested that international students ought to make more native English speaking (NES) friends (see Liu 2011); however, there are other viable social strategies, as this study will show. Brian was just one of the approximately one hundred international graduate students that were enrolled in this ESL class. What were the students' social and academic experiences outside of this class? How were the academic writing and presentation skills that they learned in this class being applied in their other academic classes? These were some of the questions that drove this research project.

There is a growing trend in American universities of recruiting and admitting an increasing number of international students, both at the undergraduate and graduate level. In fact, according to Open Doors (2012), there are over 700,000 international students in the United States, and about half of them are at the graduate level. At the university where the current research project was conducted, international students make up over $20 \%$ of the entire graduate student population, where in some fields, such as Statistics and Computer Science, the majority of graduate students are now international. The trend seems to show that STEM fields (science, technology, engineering, math) tend to host the highest amount of international students, followed by social sciences, and lastly humanities, which attracts the fewest number of IGSs (Open Doors 2012). This means that the STEM fields have a distinctly high concentration of IGSs, many of which singularly come from China, which inevitably leads to an increase in opportunities to communicate in their first language (L1) and a decrease in incentive to communicate in English.

The aim of this paper is to shed light on the choices that international graduate students make in terms of developing their social network, which in turn will provide insights regarding factors that influence language learning for this particular group of people. Particularly of importance are these early experiences, from which ultimately may account for not only the wellbeing of the student, but also the likelihood of academic success. I argue that while the social experience of the IGSs will have a great influence on their academic experience and success, it is not necessarily the case that more interactions with NESs is the optimal situation, as some of the literature has suggested.

The research questions for the current study are as follows:

1. How often are first year international graduate students using English in academic and social settings?

2. What kinds of social networks do IGSs form? 
3. What are the advantages and disadvantages of the different types of social networks?

\section{LITERATURE REVIEW}

While there are numerous studies that examine the social and academic experiences of international undergraduate students, fewer are concerned with international graduate students. The studies that solely look at undergraduate international student issues may have implications for IGSs, but the lack of literature surrounding IGSs suggests that more research needs to be done for this growing population. Of those studies that focus on IGSs, many look at acculturative stress (Constantine, Okazaki, \& Utsey, 2004; Lee, Koeske, \& Sales, 2004; Mori, 2000; Sandhu \& Asrabadi, 1994; Yeh \& Inose, 2010), and come from a psychological/counseling perspective rather than a linguistic one. These studies have identified causes for this stress, such as perceived discrimination (Dao, Lee, \& Chang, 2007; Lee \& Rice, 2007), language deficiencies (Fletcher \& Stren, 1989; Lee, Abd-ella, \& Burks, 1981), social connectedness (Yeh \& Inose 2010), and financial stress (Mori 2000), but little has been done to track and analyze language development through the critical transitional period that occurs in the first quarter of graduate school.

Constantine, Okazaki, and Utsey (2004) found that language proficiency negatively correlated with acculturative stress, and Lee, Koeske, \& Sales (2004) found that social support helped mitigate the effects of acculturative stress. In earlier studies, Selltiz, Chirst, Havel, and Cook (1963) and Heikinheimo and Shute (1986) reported that more interaction with NES students led to better social adjustment and there was a positive link between contact and adaptation. As would be expected, more advanced English skills, especially speaking skills, corresponded to both social and overall satisfaction (Fletcher \& Stren, 1989; Lee, Abd-ella, \& Burks, 1981; Yeh \& Inose, 2010). Selltiz and team (1963) found that the subjective level of confidence was the most important predictor of academic achievement; that is, how confident the student perceived him/herself to be with communicating in English. Language ability did not necessarily lead to problems with academic work, but did lead to non-academic problems.

The overall adjustment period is more complex for international students when compared to NES counterparts. Cheng, Myles, and Curtis (2004) found that the most difficult skills included leading class discussions (speaking), understanding instructions from professors (listening), and understanding the main points of a text (reading comprehension). The least important and least difficult skills identified in the survey included everyday English, for example, reading/writing emails. Andrade (2006) noted that language proficiency and cultural knowledge are two primary obstacles that 
international students face, but in the case of language proficiency, studies were inconclusive regarding its impact, or lack of impact, on academic achievement.

In regards to social experiences outside of the academic realm, language proficiency can play a major role in determining the quality and satisfaction of one's interactions with NESs (Fletcher \& Stren 1989; Lee, Abd-ella, \& Burks, 1981); however, as international communities on campus continue to gain prominence, IGSs may be more likely to seek companionship among co-nationals, either because of convenience, ease and comfort of interaction, or other factors. That said, how this will impact the student's socio-cultural adjustment and language development is rarely examined. A number of studies (Liu, 2011; Myles \& Cheng, 2003) suggested that increased interaction with NESs outside of class will improve acculturation, yet at the same time, IGSs responded with mixed feelings regarding social events such as BBQs and campus clubs, of which IGSs tend to feel like cultural outsiders and unable to fit in, thereby often avoiding such events altogether. Above all, factors such as marital status and home life of the IGS had a major impact on which people the IGS is spending time with. Andrade (2006) noted that for international students, interactions with NESs remain challenging, yet have been proven to help with overall adjustment even though gravitation towards co-nationals happens to be the more natural social approach. By using a self-reflective technique, Liu (2011), as an international student, was able to describe her own barriers and subsequently, her strategies in overcoming them. For her, the barriers to language development were reduced to a common theme: not enough interactions with NES outside of the classroom. Liu (2011) reaffirmed that being proactive is a key part of becoming an autonomous English learner; that is, someone who takes charge by creating opportunities to learn and speak English outside of the classroom. The resulting recommendation was to broaden one's NES social network as a means to maximize learning potential through increasing opportunities to speak.

Not all IGSs are able to create or join NES social networks, or even any social network, as Sawir, Marginson, Deumert, Nyland, and Ramia (2008) found that two-thirds of their 200 interviewees experienced loneliness and/or isolation during their early experiences at a university in Australia. These authors suggested that more interaction with local students will help decrease loneliness/isolation for international students, and while co-nationals can play a crucial role in the life of an international student, they cannot fully replace the student's network in the home country. Social isolation was characterized by "boredom and a sense of exclusion" (p.152), which stemmed from the need to belong to a social group. Sherry, Thomas, and Chui (2010) corroborated the findings from Sawir et al. (2008), noting that in their survey of 161 international students at the University of Toledo, 
a major theme was lack of NES friends, with only 35\% of the respondents indicating that they had successfully made friends with their American colleagues. The participants in the Robertson et al. (2000) study expressed concerns about isolation in their university life, which provided more evidence that this was a prevalent experience among international students. One of many factors for creating a successful social experience may be the willingness to communicate (WTC), defined by Gallagher (2013) as "the likelihood to initiate communication in the L2 given the opportunity" (p.56), where the WTC increases or decreases depending on the situation and is less stable than one's WTC in the L1. MacIntyre et al. (2001) describe WTC as "trait-like" (p.372), similar to other personality traits stays stable and consistent over time and across a variety of situations. However, if IGSs could develop their WTC in social situations, it would likely lead to more positive social outcomes.

The literature has acknowledged the socially isolated international student as well as the international student's inclination towards conationals, and generally recommends that international students build friendships with the local people - specifically NESs; however, what has been less discussed are the benefits of having a strong network in general, which may consist of co-nationals and other international students. Conationals who have lived in the US for a longer time can help immensely with the transition to graduate school, including help with finding housing and navigating through the local culture; in fact, co-nationals may be better equipped to help scaffold the academic experience for the newcomers, something that will be highlighted in the experiences of some of the interviewees. This help can come in many forms, for example, providing general academic advice, helping the newcomer maneuver through the academic bureaucracy, and more directly by partaking in discussion groups and discussing homework assignments.

\section{RESEARCH METHOD}

In designing my interview protocol, my goal was to maintain a certain level of informality. The intention behind this was to create a safe space for the students to talk about their experiences. I chose to conduct a semistructured interview (Meriam, 2009), which is one that has pre-written questions, but also remains open and flexible. I presumed this to be the best fit since I wanted to give the interviewee plenty of opportunities to elaborate on their experiences. In the interview process, I had to take into consideration the fact that the students were adjusting to a new setting, culture, and academic environment, while also encountering linguistic challenges. The openness and flexibility of the interview allowed me to document and detail these personal experiences. 
I divided the interview protocol into three sections: 1) questions about the student's educational background, 2) questions about language resources and opportunities on campus, and 3) questions about their social and academic experience. In reality, however, these questions and topics were not separate, but overlapping and intertwined. I first asked about the interviewee's academic background because these types of questions tend to elicit narratives and are more easily answered. In this way, the interviewee would be gently brought into the interview. The other topics in the interview were designed to be more thought-provoking in order to get the interviewee to detail the complexity of his/her experience.

\section{Participants}

Participants in the current study were recruited from the first quarter ESL class, offered to IGSs every fall, which focuses on academic writing and speaking. Students in this class had been placed in this introductory ESL class based on either by a low TOEFL score or a no-pass score on the internally administered placement exam. The three interviewees in the current study are with Brian, Amber, and Frank (pseudonyms). Brian, from China, is working on a Masters degree in Civil and Environmental Engineering. He uses English frequently in academic settings, but infrequently in non-academic settings. At the time of this study, Brian had not yet developed a social network, and remained mostly socially isolated. Amber, from Taiwan, is working on a Masters degree in Veterinary Medicine. She uses English frequently, in not exclusively, in both academic and non-academic environments. Her social network consists of international students and NESs. Frank, from Chile, is in a PhD program in Plant Sciences. He uses English infrequently in both academic and nonacademic environments. His social network consists of almost exclusively co-nationals.

I chose the interviewees based on their willingness to be interviewed as well as their different language/cultural background. The resultant interviews show a variety of experiences within the IGS community, and are representative of some of the major trends in the literature, but because of the sample size, the results from this study are not generalizable. Instead, the major themes ought to be considered as a point for future research.

\section{RESULTS}

\section{Brian (Chinese IGS)}

So in a way don't have too much chance to practice, so for the international student speaking is a big problem, seldom speak to Americans, native speakers. 
Brian, a first-year Masters student in Civil and Environmental Engineering, was a student of mine in the introductory ESL class, and one of the reasons for pursuing this project. During the interview, Brian gave an honest account of his experience as an IGS, including his perspective on what IGSs go through in their transition to graduate school, in particular with regards to social experiences. Brian did not integrate easily, and gave an account of the loneliness and isolation that he felt as an international graduate student, particularly upon arrival, being far away from family and familiar settings. In addition, Brian's talked about his difficulty to befriend American students, as in the following excerpt:

Brian: For international student, actually it is hard to make friends with native Americans, so most of the time they just group together with other international students, so we don't have the surrounding or atmosphere of the language, but you know, we can understand each other, but not so good, just understand.

As a result of not integrating easily into the host culture, Brian endured an isolating transition. Of the interactions that he had with others, he mentions that most of these interactions were with international students, largely because they can understand each other more easily. As a corollary to gravitating towards other NNESs, Brian implies that he seeks situations where making mistakes is acceptable. Perhaps, in this way, he is able to interact with others, using English, and still feel like it is a safe or nonjudgmental setting. In the next excerpt, Brian talks about the social importance of the ESL class for new international graduate students:

Brian: Yeah, when you come here, you know nobody, so you are pretty lonely, just live by yourself, if you have something uncomfortable or sad, you don't have nobody to communicate with, everybody has a hard time just come to [this university].

Daniel: Yeah, at first.

Brian: So, I think for the new students, I suggest that, for [the ESL class], they should like have the contact information of everybody, or make a group, make friends with each other, because they are the first group of people you meet here, they can support each other.

Brian reinforces the idea of the ESL class as an opportunity to make friends with other international students, and the importance of making connections early on, especially since graduate students, like Brian, often live on their own. He seems to be especially keen on finding support, as the support network was lacking in his early experiences. In addition to the lack of 
support, the social isolation correlates with a lack of meaningful opportunities to speak in English, and impacted Brian's speaking confidence.

Difficulties with speaking and confidence were brought up and expounded on throughout the interview, and, unsurprisingly, Brian reported using English in academic settings $60-79 \%$ of the time, but only $20-39 \%$ of the time in non-academic setting, demonstrating that the majority of his social interactions took place in his L1.

In the realm of academic experiences, Brian mentioned having to present in his major course, something that he felt extremely nervous about doing, which contrasted to his experience in the ESL class, where he felt comfortable presenting. The ESL class was a safer space for Brian to present and he excelled; by contrast, he struggled with his presentation in his major course not because of the content, but more because of the inevitable question/answer period that would come afterwards, as shown in the following exchange:

Brian: In [the ESL class] everyone is from a different major, you just have a general idea of your research, but in a major course, they understand what you see and maybe they can point out why you are wrong.

Daniel: Tell me about that experience, presenting in class.

Brian: It is like we are doing a research based on computer calculation to get the best design for material, I think the report I did was pretty good, pretty nice, and the presentation was based on the report, I tried to make everything in the report on the slides, I think I relied too much on the slides, we have a lot of data, I don't think I need to talk too much before the data, but the truth is I tried to talk to about datas, I failed to describe the data, why it's the best, sometimes people ask why? What is something? Oh, you didn't prepare for it, so it's stuck.

Daniel: Was that your first presentation?

Brian: Yeah, first academic presentation

In this excerpt, Brian is talking about feeling stuck during the question-andanswer sections of the presentation. Brian knew the material, and even practiced and prepared, but there wasn't any clear way to prepare for the Q \& A session, and quite probably his nervousness negatively affected his performance. Unsurprisingly, Brian felt like speaking was his biggest weakness.

What emerges from these interview excerpts is the link between opportunities to speak and speaking confidence. Brian has started his graduate program with a weak social network, and when there were 
interactions with other, Chinese was used. Whether or not Brian is able to successfully acclimate to, or at the very least cope with, the local culture may be crucial to his overall experience in graduate school. In order to find out, more interviews over time with Brian will need to be conducted.

\section{Amber (Taiwanese IGS)}

Study hard, don't think you are here for your life, you are here for your education, you are not here to have a life, you are here to study, don't be afraid to talk to people.

At the time of the study, Amber was a first year Masters student in Public Health and Veterinary Medicine. She spent the vast majority of her upbringing and adult life in Taiwan, where she graduated from university. She seemed to be the most culturally adjusted of all the interviewees, which may be accounted for by the fact that she already had some extended family in Southern California. Amber represents a socially successful IGS with a strong support network who has acculturated and formed a network of friends. Possibly her already existing familial network gave her confidence, and the fact that she had spent a year in the states beforehand made the cultural transition less of a shock. Amber has an international social network consisting of people from her country (Taiwan) and other countries, and sees the benefit of having co-nationals in one's social network. Even though she has a network of international people, Amber is primarily using English in her day-to-day interactions. Among the interviewees, Amber had the most strategic approach to finding friends, as expanded on in the following excerpt:

Daniel: I want to ask about your transition, socially and academically, first socially.

Amber: I think common in Asia, most people stick together all the time because a class stays together for the whole year, so you know everyone well, but here some of those people don't really talk to each other, people find a small group and stick together forever, sometimes it's hard for people to get in these small groups. But I found my small group anyways.

Daniel: Was that your strategy?

Amber: Well I have been here before for one year and I was shy, waiting for people to talk to me, but people didn't talk to me, okay, so I need to talk this time, so I try to talk more, and my classmates are amazing to me, so that's good.

This is an example of how Amber was able to adapt easily to her new surrounding, and as a result of her flexibility she was able to achieve social 
success. She talked about how she spent most of her time with international students from other countries, which provided her with ample opportunities to speak and interact in English in a safe environment. Given that Amber creates these opportunities for herself, she would be considered an autonomous English user in the eyes of Liu (2011), and her high WTC (Gallagher 2013) justifies her experience of being able to adapt easily to the host culture.

Amber even had the wherewithal to recognize that the new social environment required interaction in new settings, perhaps even in settings that are looked down upon in her home culture. In this next interview excerpt, Amber talks about hoe she goes to bars in the United States as a place of interaction and socializing even though bars are places where bad students go in her culture.

Daniel: You feel like you found your group?

Amber: Yeah, most people cannot really find their group

Daniel: In one year, you are halfway done

Amber: I know, it's fast. I think people here like to hang out in the bar, which is pretty different in Asia, because bar is only like for bad student, someone will hang out late in the night, my parents wouldn't like me to go to a bar, but here I see why people go, they don't have anywhere else to go.

Amber shows her ability to not only recognize the cultural differences, but she chooses to go beyond the boundaries of her own cultural norms in order to achieve her goals of creating a viable social network.

In these interview excerpts, Amber shows her outgoing demeanor and her drive to be social, which led to many successful friendship with other international students. This international social network has provided Amber with unending opportunities to speak in English and the support needed for her to be successful in her program.

\section{Frank (Chilean IGS)}

I try to talk to American people, because here we are too many

Chilean. I feel like, not always, I talk too much in Spanish.

Frank is a first-year international graduate student from Chile studying plant sciences. He never imagined coming to the United States for a graduate program. Recognizing his weaknesses in speaking, he arrived early for an intensive English program that lasted three quarters, during which time he made some connections with professors on campus. He then took TOEFL a few times, and ultimately scored high enough to be a competitive candidate; his success on TOEFL, coupled with his connection 
with a professor on campus, led to the acceptance to his graduate program.

Frank reported using English rarely in academic settings, and almost never in non-academic settings. Overall, he uses English the least out of all of the interviewees. As a testament to his low frequency of English use, Frank shared the fact that in the majority of his time spent in social situations, he communicates in his native language, Spanish. He justified this by noting the fact that the university has a tight-knit community of people from Chile, leading him to interact in that social circle easily. In this excerpt, Frank shares his early experiences, interacting with his Chilean roommate, which sets him on his social path.

Daniel: So you arrive in California, and what is that like?

Frank: Okay I come [to this university] to live with Chilean friend and okay, was a family and for me was easy because I can speak with him in Spanish and he help me with so many [things], and I arrive for study in the extension.

Daniel: Yeah

Frank: And I spend three quarter there and at this time I begin to apply for the scholarship and in there I contact with a professor here and okay finally he gave me the possibility for working here in the university and I have to leave extension for that but I don't know my level I think that I got tools but finally my grammar is no good, my speaking is no good but I can communicate my ideas, but not so good, but usually the people can understand.

This early experience of socializing with a co-national roommate led to an opportunity to join the larger Chilean community, where Frank found comfort and cultural familiarity. As a result, Frank gained enough friends to satisfy his social needs, and did not feel the need to make friends with NESs. However, the fact that all of his friends were co-nationals, sharing the same language, meant that almost all of his interactions were in Spanish and his English speaking skills were slower to develop.

In this next excerpt, the lack of interaction in English culminates in the feeling of uncomfortable in a social situation that requires him to use English. In fact, he feels even more uncomfortable in a social situation compared to an academic one. In this excerpt, Frank addresses his experience in social and academic settings. In the first part, he is referring to making a quick comeback to someone in a social situation:

Frank: Yeah, here the something happen I don't feel too much confidence say something or I don't know I'm always looking but no doing something.

Daniel: Okay, yeah, sure. 
Frank: I don't know for me it's more difficult, I don't know.

Daniel: Like you might want to say a silly comment, but...

Frank: I'm not sure if it would be good or not and also sometimes on the street I can no understand all the people and my listening in the social area is no the best I think in the academics is good because the people speak very clear and they try to give you an idea but on the street if someone say something that I didn't pick up or didn't pay attention and I didn't hear I don't know.

In the interview, Frank gave as an example a hypothetical situation of something happening abruptly, like a glass falling from a table, where he would automatically know how to respond in Spanish, perhaps even with a witty or quirky comment. In English, however, the time that it would take to process something to say would diminish the content of the remark, since timing is an important aspect of spoken interactions.

Frank is representative of IGSs who choose to primarily, if not exclusively, socialize with co-nationals, and the reason is that of ease and convenience. A network of co-nationals can be strengthening and supportive, and for many IGSs having such a network trumps the need to seek out opportunities to speak in English. Frank, as a result, seemed happy and well-adjusted to his life as a graduate student, although perhaps he will find himself lacking the culturally acceptable remark in certain social situations.

\section{DISCUSSION AND CONCLUSIONS}

The three interviewees in the present study show a snapshot of the variety of social networks that IGSs may form early on, and motivate further research as to the impact of social experiences on language learning and academic achievement. Each IGS detailed in this study had a different social experience, including Brian, who felt isolated, but had some interaction with foreign students, Amber, who used English frequently with other NNESs, and Frank, who interacted predominantly in Spanish with co-nationals. Each of these social experiences is unique, and there are characteristics of each one that will impact language learning in unique ways.

As educators, researchers, and administrators, we would be concerned about students like Brian who have not yet developed a support network. We should be cognizant that the transition period to graduate school in another country presents many challenges, and without support from peers, these challenges are even more pronounced. ESL classes are helpful for introducing students to each other, but more programming and campus event many be needed to promote social success in the IGS community. 
Amber was successful in achieving social support through her own willpower and proactive demeanor. As a result, she became a part of a strong social network, one that provided her with lots of speaking opportunities. The literature (e.g., Liu 2011) may still recommend that Amber interact more with NESs; however, her international network has led to a sense of ease and ability to acculturate, evidence that seeking out NESs is not necessarily the best strategy.

In the case of Frank, who had immersed himself in a strong conational community, he was able to build his social network easily, but because the vast majority of his interactions take place in his L1, it is unclear how his long-term language development will be affected. Still, for someone who is joining a new cultural environment, the strategy of befriending co-nationals may be a wise choice, especially in places where strong co-national communities exists. These preexisting communities are valuable sources of support for new students, and they are likely to have an increasing importance as more international students matriculate. Because co-national communities tend to be easy to join, more research needs to be done on the impact of being immersed in such a community on English language development.

The current study considers the social experiences of three IGSs, which is not enough to attain generalizable results. The IGSs profiled in this study are representative of larger trends, but do not represent every social experience. That said, it is important to take notice in these trends, measure their impacts, and continue to research how they change over time.

\section{IMPLICATIONS}

The data and analyses within this paper represent a starting point for a greater project that seeks to identify and explore salient issues that international graduate students face in the first year of their graduate program. The interview portion contributed to understanding some of the experiences of international graduate students by giving them a voice. The interviewees' accounts shed light on the complexity of their experiences by giving concrete examples and instantiations of the struggles that IGSs face in garnering healthy social networks. Further research on this topic would include first and foremost interviewing more international graduate students, and not only first-year students, but also students who are further along in their program. By interviewing those who have been around for a longer period of time, it would be possible to see what the social and academic experience looks like in more developed stages, and as they proceed through critical, gatekeeping stages in their program (becoming a TA, writing qualifying papers, taking the qualifying exam, etc.). Also, of interest would be to observe IGSs in their field specific classes, as well as situations where 
IGSs interact with colleagues and professors outside of the 'safe' space that ESL classes often provide; in other words, shadow students in both academic and non-academic settings. Finally, I think that it would be crucial to collect more data regarding the social networks of IGSs to better understand the role of social networks in language learning. Although this initial study is limited in scope, it has raised more questions for future studies.

\section{Appendix - Interview questions}

\section{Topic 1: Background Information and English Language}

1. Please tell me about your educational background and how you came to study at this university.

2. What were the hardest and easiest parts about transitioning to life at this university socially?

3. What were the hardest and easiest parts about transitioning to life at this university academically?

4. I'd like to ask about how you doing in terms of language. First, in speaking, reading, writing, and listening in the academic setting, and also in the social setting.

5. And in which skill area have you improved the most, and how do you account for that?

\section{Topic 2: Opportunities and Resources}

6. What resources has your department offered you in terms of English support? This can be in the form of tutoring, meetings, etc.

7. What else would you like to see available at your campus in terms of English resources?

8. In what ways was this class helpful, and in what ways do you think that this class could be improved to better suit your needs?

\section{Topic 3: Academic experience}

9. What are some challenges that international students face that American born students may not?

10. Regarding your expectations of your academic program, what was the most surprising thing about your program? In what ways has your program met your expectations?

11. What do you wish you knew before coming to university (about life, academics, your program)?

12. If you have been a TA, please tell me about that experience. If you haven't, what would you look forward to, and what would concern you about being a TA?

13. Tell me about your experience in your classes (note-taking, listening comprehension, opportunities to participate).

14. Tell me about your experience doing research.

15. If you were struggling with an assignment/paper, what would you do? Who would you see, how would you handle this situation?

16. Now that you have completed a quarter here, what advice do you have for international graduate students who will be starting next year? 


\section{REFERENCES}

Andrade, M. S. (2006). International students in English-speaking universities. Journal of Research in International Education, 5, 131-154.

Berg B.L., \& Lune, H. (2004). Qualitative Research Methods for the Social Sciences. Needham Heights, MA: Pearson.

Cheng, Y., Myles, J., \& Curtis, A. (2004). Targeting language support for non-native English-speaking graduate students at a Canadian university. TESOL Canada Journal, 21(2), 50-71.

Constantine, M. G., Okazaki, S., \& Utsey, S. O. (2004). Self-concealment, social self-efficacy, acculturative stress, and depression in African, Asian, and Latin American international college students. American Journal of Orthopsychiatry, 74, 230-241.

Coxhead, A. (2000). A New Academic Word List. TESOL Quarterly, 34(2), 213238.

Dao, T. K., Lee, D., \& Chang, H. L. (2007). Acculturation level, perceived English fluency, perceived social support level, and depression among Taiwanese international students. College Student Journal, 41(2), 287-295.

Fletcher, J., \& Stren, R. (1989). Language skills and adaptation: A study of foreign students in a Canadian university. Curriculum Inquiry, 19(3), 293-308.

Heikinheimo, P. S., \& Shute, J. C. (1986). The adaptation of foreign students: Student views and Institutional Implications. Journal of College Student Personnel, 27(5), 399-406.

Gallagher, H. C. (2013). Willingness to communicate and cross-cultural adaptation: L2 communication and acculturative stress as transaction. Applied Linguistics, 34(1), 53-73.

Lee, J., Koeske, G. F., \& Sales, E. (2004). Social support buffering of acculturative stress: A study of mental health symptoms among Korean international students. International Journal of Intercultural Relations, 28(5), 399-414.

Lee, J. J., \& Rice, C. (2007). Welcome to America? International student perceptions of discrimination. Higher Education, 53, 381-409.

Lee, M. E., Abd-ella, M., \& Burks, L. (1981). Needs of foreign students from developing nations at U.S. colleges and universities. National Association for Foreign Student Affairs, Washington, DC.

Li, L., Mazer, J. P., \& Ju, R. (2011). Resolving international teaching assistant language inadequacy through dialogue: Challenges and opportunities for clarity and credibility. Communication Education, 60(4), 461-478.

Liu, L. (2011). An international graduate student's ESL learning experience beyond the classroom. TESL Canada Journal, 29(1), 77-92.

MacIntyre, P. D., Baker, S. C., Clement, R., \& Conrod, S. (2001). Willingness to communicate, social support, and language-learning orientations of immersion students. SSLA, 23(3), 369-388.

Manese, J. E., Sedlacek, W. E., \& Leong, F. T.L. (1988). Needs and perceptions of female and male international undergraduate students. Journal of Multicultural Counseling \& Development, 16(1), 24-29.

Meriam, S. B. (2009). Qualitative research. San Francisco, CA: Jossey-Bass.

Mitchell, R., \& Myles, F. (2004). Second language learning theories $2^{\text {nd }}$ Edition. London: Hodder Education. 
Myles, J., \& Cheng, L (2003). The social and cultural life of non-native English speaking international graduate students at a Canadian university. Journal of English for Academic Purposes, 2, 247-263.

Open Doors (2012). Fast Facts. Retrieved from http://www.iie.org.

Perrucci, R., \& Hu, H. (1995). Satisfaction with social and educational experiences among international graduate students. Research in Higher Education, 36(4), 491-508.

Robertson, R, Line, M, Jones, S., \& Thomas, S (2000). International students, learning environments and perceptions: A case study using the Delphi technique. Higher Education Research \& Development 19(1), 89-102.

Sandhu, D. S., \& Asrabadi, B. R. (1994). Development of an acculturative stress scale for international students: Preliminary findings. Psychological Reports, 75(1), 435-448.

Sawir, E., Marginson, S., Deumert, A., Nyland, C., \& Ramia, G. (2008). Loneliness and international students: An Australian study. Journal of Studies in International Education, 12(2), 148-180.

Sawir, E. (2005). Language difficulties of international students in Australia: The effects of prior learning experience. International Education Journal, 6(5), 567-580.

Scheider, M., \& Fujishima, N. (1995). When practice doesn't make perfect: The case of a graduate ESL student. In Academic Writing in a Second Language: Essays on Research and Pedagogy (pp. xx-xxx). Norwood, NJ: Ablex Publishing Corporation.

Selltiz, C., Chirst, J. R., Havel, J., \& Cook, S. W (1963). Attitudes and social relations of foreign students in the United States. Minneapolis, MN: University of Minnesota Press.

Sherry, M., Thomas, P., \& Chui, W. International students: A vulnerable population. Higher Education, 60, 33-46.

Yeh, C. J., \& Inose, M. (2010). International students’ reported English fluency, social support satisfaction, and social connectedness as predictors of acculturative stress. Counseling Psychology Quarterly, 16(1), 15-28.

DANIEL MOGLEN, M.A., is a PhD candidate in Linguistics. His research interests include language assessment, placement tests, and second language writing. Email: djmoglen@ucdavis.edu

Manuscript submitted: February 15, 2015

Manuscript Revised: November 30, 2015 Accepted for publication: February 21, 2016 